\section{Urgent and Massive Investment in US \\ Public Health Infrastructure Will Help to Stop the Spread of SARS-CoV-2 Virus and Deaths from COVID-19}

Talkad S. Raghuveer, M.D. ${ }^{1}$, Dennis Kriesel, B.A., MPA² 'University of Kansas School of Medicine-Wichita, Wichita, KS

Department of Pediatrics

${ }^{2}$ Kansas Association of Local Health Departments, Topeka, KS Received Jan. 6, 2021; Accepted for publication Feb. 11, 2021; Published online March 19, 2021 https: /oi.org 10.17161 lijm.voll415061

The COVID-19 pandemic is surging in the U.S. with more than 27 million cases and 446,000 deaths. ${ }^{1}$ COVID-19 is a leading cause of death in the U.S. ${ }^{2}$ The pandemic has exposed significant weaknesses of the U.S. public health system, which has long suffered from inadequate funding and other resources needed to address public health emergencies like the COVID-19 pandemic. Per capita expenditures among local health departments (LHDs) decreased $30 \%$ between 2008 and 2019.3 In 2018, $23 \%$ of LHDs reported job losses due to layoffs or attrition. In 2019 , nearly $65 \%$ of LHDs received no extra funding and $81 \%$ reported funding cuts for preparedness and response. ${ }^{4}$

Most states (30) have a decentralized public health system, with local governance. The majority (61\%) of LHDs serve less than 50,000 people and $35 \%$ have less than 10 full time staff. ${ }^{3}$ Mitigation strategies, such as mask mandates, the capacity to conduct case investigation effectively, and contact tracing vary among LHDs and across states. Both large and small LHDs have been overwhelmed, but the impact has been greater among small, rural health departments. Nationally, only $28 \%$ of local health departments have epidemiologists or statisticians on staff. In addition, the combination of unsustainable workloads, pushback on mitigation strategies, threats, and political pressures has led to a high turnover of staff. Since April, more than 100 public health leaders across the U.S. have retired, quit, or been fired. ${ }^{5}$

\section{What is happening at the local level?}

Kansas can provide an example for what is happening at the local level, and this could be true in other states as well. The LHDs in the state of Kansas are strained by the volume of case investigations and contact tracing, particularly given the rapidly rising COVID-19 caseload (> 284,000 positive cases, $>$ 8,840 hospitalizations, and $>4,300$ deaths). ${ }^{6}$ A recent survey of LHDs in Kansas showed that the LHD staff are devoting all their time to stop the spread of SARS-CoV-2, many working over weekends. ${ }^{7}$ Despite an increase in COVID-19 cases, the number of staff involved in contact tracing has not increased, especially in smaller LHDs, and funding has not increased in many LHDs. In addition, LHD staff reported a sense of being overwhelmed. Since the start of the pandemic, there also has been a loss of $16 \%$ of the local health administrators and $20 \%$ of local health officers.

The Kansas Department of Health and Environment (KDHE) has pools of both case investigators and contact tracers, but the increasing volume of case counts has put a strain on both state and local health department capabilities. On average, a case investigator can complete 10 - 15 cases per day. With a surge in COVID-19 positive cases, it is no longer possible to complete a case investigation in the state of Kansas within 24 hours of a positive test result.

\section{KANSAS JOURNAL of MEDICINE}

KDHE is gearing up to train LHDs on its Salesforce (https://www. salesforce.com/) tool. This is a software system to augment the traditional telephone call approach to case investigation and contact tracing. The system integrates into the Epitrax software system, ${ }^{8}$ where all the cases are entered for the state of Kansas, and it could alleviate some of the time constraints. But the volume of cases has impacted the speed of the Epitrax and direct data entry. In addition, the Kansas Legislature passed HB 2016 in June 2020 (www.kslegislature.org/li_2020s/ b2020s/ measures/hb2016/), a compromise legislation designed to do multiple COVID-19 related activities, but it also limited the powers of the Governor and allowed the legislature to have more direct control over the pandemic response. It also enabled county commissioners to review, amend, and revoke local health officer orders.

\section{What is way forward to help local health departments?}

The SARS-CoV-2 virus does not limit itself to county or state borders. On March 13, 2020, the COVID-19 pandemic was declared a national emergency. ${ }^{9}$ This allowed the federal government to deliver funds and other resources to state and local governments but has not stopped the surge of COVID-19. The countries that successfully have controlled the spread of SARS-CoV-2, such as South Korea and Taiwan, have central agencies that have resources to ramp up contact tracing and effectively quarantine contacts. The U.S. response, in comparison, largely has been the responsibility of LHDs and state health departments. The U.S. public health agencies need resources to implement a more coordinated pandemic response. For example, the National Disaster Medical System and the U.S. Public Health Service plan to establish a Ready Reserve Corps which could be expanded to provide LHDs with case investigators, contact tracers, and other staff. ${ }^{10}$ One of the alternative options would be to create a federal agency (the Federal Pandemic Response Agency) with enough resources to coordinate the public health measures. This agency could be part of the U.S. Department of Health and Human Services, working with the White House Pandemic team and CDC COVID-19 response team, to produce current, scientific national guidelines. In addition, the agency could have enough resources to help LHDs with more funding, staffing, and training for the duration of the pandemic.

\section{What else can be done to help with efforts of LHDs' directly or indirectly?}

Research. There is a need for research to understand the spread of the virus in various communities. The LHDs have data of positive cases and clusters, however, there has not been much research of this dataset as the LHD staff are overstretched with little or no collaboration with academic researchers. As Americans spend more time indoors, there is an urgent need for updated recommendations from the American Society of Heating and Air Conditioning Engineers (ASHRAE) regarding air handling (e.g., number of air exchanges, upper room germicidal UV fixtures). ${ }^{11}$ In addition, national guidelines are needed to decide when to deploy (and when to stand down) the state National Guard resources (the National Guard has been mobilized in some states for 
ment, all the county health departments, all the hospital systems in the state of Kansas, and all the pharmacies in the state to work together.

\section{CONCLUSIONS}

The COVID-19 pandemic is an immense human tragedy. The effects short durations). In addition, it is important to research the needs of LHDs to improve their efforts to contain the spread of SARS-CoV-2.

Improved Messaging. Lack of trust in guidelines to control the virus persists among segments of society. There are cognitive bias and errors in processing the public health guidelines. ${ }^{12}$ To improve trust and overcome the cognitive errors, there is an urgent need to improve messaging with the help of professionals (e.g., professional advertising agencies, social media, use of "influencers" on social media, U.S. Postal Service mail, use of famous personalities such as sports and film stars). In addition, misinformation on social media needs attention. ${ }^{13}$ Mask mandates and other public health efforts have been met with hesitancy without effective messaging.

SARS-CoV-2 Testing and Availability of Masks/Hand Sanitizers in the Community. The results of testing for SARS-CoV-2 takes more than three days ${ }^{7}$ in many LHDs and this needs to be addressed urgently to stop the spread of the virus effectively. LHDs may need resources to provide masks and hand sanitizers to the community at large, as it may not be enough to mandate masks unless masks are easily available.

COVID-19 Vaccines. Health care workers and residents of longterm care are receiving COVID-19 vaccines. LHDs will need increased staffing/resources to administer vaccine to the community in the near future. However, despite the availability of vaccines, it is important to continue public health measures. Hesitancy and resistance to COVID19 vaccine are possible and effective messaging may help overcome it. ${ }^{13}$ Genetic variants of the spike protein of SARS-CoV-2 virus are emerging, and whether the current vaccines will be helpful against these variants is not known. ${ }^{14}$ This worrisome development emphasizes the need for greater public health measures to prevent the spread of the SARS-CoV-2 virus and the spread of the variants of the virus.

The state of Kansas has received 552,775 doses of the COVID19 vaccines. As of February 11, 2021, 331,022 people in Kansas have received the vaccine (248,977 first dose and 82,045 second dose). ${ }^{6}$ There is hope that all the states in the U.S. will receive significantly increased distribution of COVID-19 vaccines soon. If such an increase of vaccine doses comes about, it may be time to vaccinate as many people as possible, as soon as possible, to achieve herd immunity.

If we assume that nearly 1.4 million Kansans are eligible and sign up for the vaccine, the number of people who need to vaccinated daily needs to increase significantly. For example, nearly 7,700 people need to be vaccinated daily (seven days a week) for six months (double that number if we need to vaccinate everyone in three months), to receive at least one dose of the available vaccine. If one nurse or pharmacist is able to give vaccine to an average of 60 people, there is a need for nearly 125 to 150 such health care persons available to complete this task. There is, in addition, a need to store these vaccines properly. This massive vaccination campaign will need significant planning, coordination, and conveying information regarding ongoing efforts to the public in real time. This effort may need the involvement of the state health departof the pandemic have been particularly harsh in the U.S., with COVID19 deaths close to exceeding 500,000. The pandemic has affected all aspects of life in the U.S. It is estimated that the cost of the pandemic may exceed $\$ 16$ trillion. ${ }^{15}$ It may be more difficult to estimate the harm to the community at large (closure of small businesses, job losses, evictions, school closures, and mental health).

To stop this pandemic, LHDs are urgently in need of significantly more resources that includes increased access to rapid and reliable tests, increased staff for rapid case investigations, contact tracing, resources for effective quarantine, and increased staffing/equipment for vaccinating the community. There is an urgent need for massive investment in public health in the U.S. to control not just the current pandemic but future pandemics.

\section{ACKNOWLEDGMENTS}

The authors wish to thank Charlie Hunt, MPH, Senior Analyst, Kansas Health Institute, for his help with background material.

\section{REFERENCES}

${ }^{1}$ U.S. Centers for Disease Control and Prevention. CDC COVID Data Tracker.Covid.cdc.gov/covid-data-tracker/\#cases_casesperlooklast7days. Accessed February 11, 2021,

${ }^{2}$ Woolf SH, Chapman DA, Lee JH. COVID-19 as the leading cause of death in the United States. JAMA 2021; 325(2):123-124. PMID: 33331845.

3 National Association of County and City Health Officials. National Profile of Local Health Departments. 2020. https://www.naccho.org/uploads/ downloadable-resources/Programs/Public-Health-Infrastructure NACCHO_2019_Profile_final.pdf.

${ }^{4}$ Spinner T. More than 9 in 10 Americans are endangered by the underfunding of local public health. NACCHO Voice 2020. https://www.naccho. org/blog/articles/more-than-9-in-10-americans-are-endangered-by-theunderfunding-of-local-public-health.

5 Smith MR, Young K. Public health programs see surge in students amid pandemic. November 17,2020. https://khn.org/news/public-health-degreeprograms-see-surge-in-students-amid-pandemic/. Accessed January 6, 2021.

${ }^{6}$ Kansas Department of Health and Environment. KDHE Coronavirus (COVID-19) Response. www.coronavirus.kdheks.gov. Accessed February $11,2021$.

7 Raghuveer TS, Zackula RE, Wittler RR. Second survey of county health departments of Kansas and COVID-19: Time for change in model for pandemic response. Kans J Med 2020; 13:290-299. PMID: 33312412.

${ }^{8}$ Kansas Department of Health and Environment. EpiTrax user guide. July 26, 2019. https://kdheks.gov/epi/download/Epitrax_user_guide.pdf. Accessed January 6, 2021.

9 The White House. Proclamation on Declaring a National Emergency Concerning the Novel Coronavirus Disease (COVID-19) Outbreak. March 13, 2020. https://www.whitehouse.gov/presidential-actions/ proclamation-declaring-national-emergency-concerning-novel-coronavirus-disease-covid-19-outbreak/. Accessed January 6, 2021.

${ }_{10}$ United States Government Accountability Office. GAO-20-525. Public health preparedness: HHS should take actions to ensure it has an adequate number of effectively trained emergency responders. June 2020. https:// www.gao.gov/assets/710/707710.pdf. Accessed January 6, 2021.

${ }_{11}$ Nardell EA, Nathavitharana RR. Airborne spread of SARS-CoV-2 and a potential role for air disinfection. JAMA 2020; 324(2):141-142. PMID: 32478797.

${ }^{12}$ Halpern SD, Truog RD, Miller FG. Cognitive bias and public health policy during the COVID-19 pandemic. JAMA 2020; 324(4):337-338. PMID: 32597963.

${ }^{13}$ Merchant RM, South EC, Lurie N. Public health messaging in an era of social media. JAMA 2021; 325(3):223-224. PMID: 33393964. 
${ }^{14}$ Massacci A, Sperandio E, D’Ambrosio L, et al. Design of a companion bioinformatic tool to detect the emergence and geographical distribution of SARS-CoV-2 spike protein genetic variants. J Transl Med 2020; 18(1):494. PMID: 33380328.

${ }^{15}$ Cutler DM, Summers LH. The COVID-19 pandemic and the $\$ 16$ trillion virus. JAMA 2020; 324(15):1495-1496. PMID: 33044484.
KANSAS JOURNAL of MEDICINE COVID-I 9 AND PUBLIC HEALTH continued.

Keywords: COVID-19, pandemics, public health, Kansas 